\title{
Hereditary pancreatic hypoplasia, diabetes mellitus, and congenital heart disease: a new syndrome?
}

Tohru Yorifuji, Masahiko Matsumura, Takehiko Okuno, Ken Shimizu, Takako Sonomura, Junko Muroi, Chieko Kuno, Yasuo Takahashi, Takehiko Okuno

\begin{abstract}
We report on a Japanese family with hereditary pancreatic hypoplasia, diabetes mellitus, and congenital heart disease. The disease was apparently inherited as an autosomal dominant trait. The patients in this famly had no major anomalies other than those of the heart and pancreas. To our knowledge, this combination has not previously been reported.
\end{abstract}

(f Med Genet 1994;31:331-333)

\section{Case reports}

\section{FAMILY HISTORY}

The parents are both Japanese and non-consanguineous. The pedigree of the family is shown in fig 1. The mother underwent cardiac surgery at 19 years of age because of patent ductus arteriosus and atrial septal defect. After her third pregnancy, at the age of 28 years, she was diagnosed as having diabetes mellitus. Initially, her diabetes was well controlled with dietary therapy alone, but at the age of 30 years she began to need oral hypoglycaemic agents and currently her diabetes is controlled by daily subcutaneous insulin injection. Other than that, she has no anomalies and her IQ is normal. The father has no significant medical history and is apparently healthy. Their first child (female) was born at 32 weeks' gestation and had a birth weight of $1800 \mathrm{~g}$ (appropriate for gestational age). She died soon after birth without detailed medical examination. Their second child (female) was born at 32 weeks'

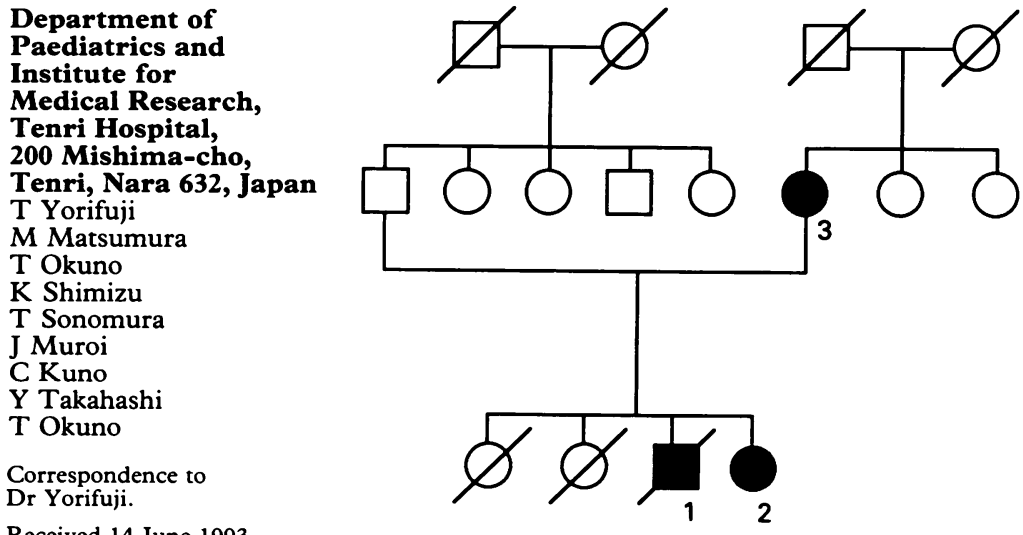

Received 14 June 1993 Revised version accepted for publication 11 October 1993
Figure 1 The pedigree of the family. Numbers indicate the case number in the text. gestation and had a birth weight of $1760 \mathrm{~g}$ (appropriate for gestational age). She also died soon after birth from unknown causes. No detailed medical record is available for the second child either.

CASE 1

The third child (male) was referred to our hospital at 2 years 7 months of age because of vomiting and poor appetite. He was born at 32 weeks' gestation and had a birth weight of $1800 \mathrm{~g}$ (appropriate for gestational age). The pregnancy was complicated by toxaemia and premature rupture of the membranes. The mother was not diabetic, nor under the influence of drugs or other chemicals during the pregnancy. Although he had moderate developmental delay (head control at 6 months, sitting at 18 months), his general condition had been fair until one month before admission when he developed measles. After this episode, his appetite was poor and five days before admission he began to vomit frequently. On admission, he was acutely ill although consciousness appeared to be normal. No external dysmorphic features were noted. A harsh midsystolic heart murmur was heard over the left sternal border. He also had clubbing of the fingers. His height was $77.0 \mathrm{~cm}(-3.9 \mathrm{SD})$ and weight was $7700 \mathrm{~g}(-3.3 \mathrm{SD})$. Initial laboratory examination showed hyperglycaemia $(37.7 \mathrm{mmol} / \mathrm{l}$ or $680 \mathrm{mg} / \mathrm{dl})$ and massive glucosuria with ketonuria. Insulin therapy was started immediately under a diagnosis of diabetic ketoacidosis. Although his blood sugar was controlled, he had convulsions on the third day in hospital. CT scan of the brain showed a mass in the right occipital area of the brain. He died of increased intracranial pressure on the 34th day in hospital. Necropsy showed severe hypoplasia of the pancreas (fig 2). The pancreas could not be identified macroscopically and in the normal pancreatic position there was only a thin segment measuring $3.4 \mathrm{~cm} \times 0.9 \mathrm{~cm} \times 0.4 \mathrm{~cm}$. Microscopically, only a remnant of pancreatic tissue was identified in and adjacent to the duodenal submucosa and the islets of Langerhans were somewhat atrophic. No inflammatory changes were found in the pancreas. In addition, he had combined cardiac anomalies consisting of transposition of the great vessels, ventricular septal defect, pulmonary stenosis, and atrial septal defect. He also had a necrotic brain mass caused by Mucor infection. 


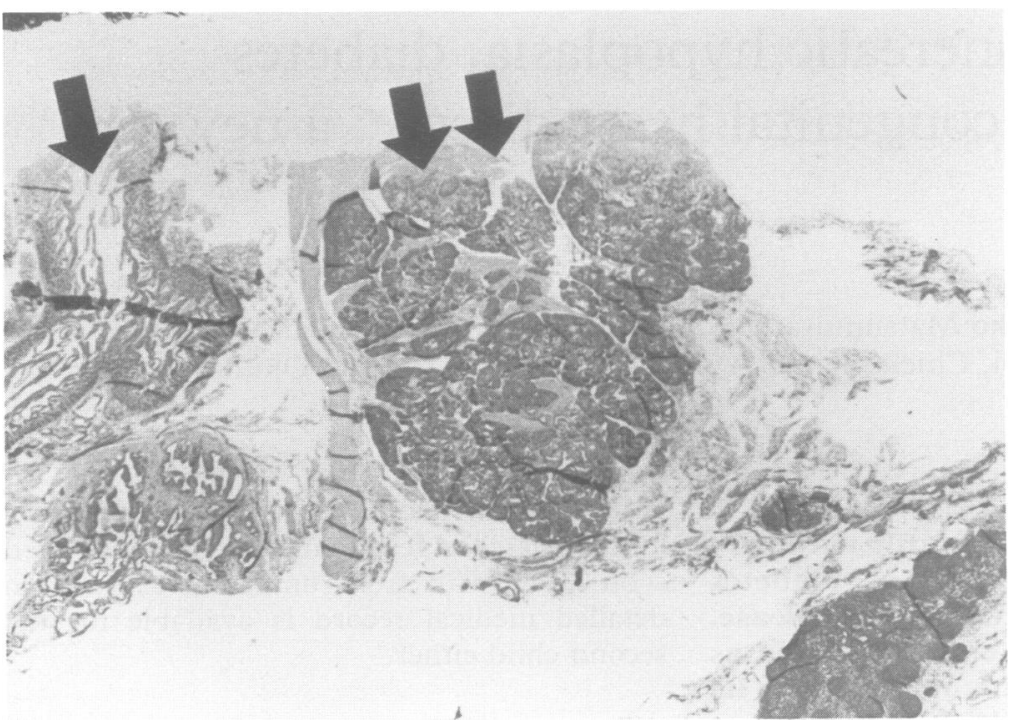

Figure 2 Histopathological findings of case 1. The remnant of pancreatic tissue (double arrow) was embedded in the duodenal submucosa. A single arrow indicates the duodenal mucosa.
IQ was normal. Laboratory examination showed that she had hyperglycaemia $(12.5 \mathrm{mmol} / 1$ or $226 \mathrm{mg} / \mathrm{dl})$ with mild ketosis. Her $\mathrm{Hb} \mathrm{A}_{1}, \mathrm{Hb} \mathrm{A}_{\mathrm{lc}}$, and serum fructosamine were $17.9 \%, 12 \cdot 8 \%$, and $673 \mu \mathrm{mol} / 1$, respectively. Daily urinary excretion of C-peptide was measured twice and was 8.5 and $32.9 \mu \mathrm{g} /$ day, respectively. Anti-islet cell antibody was negative. Chromosome analysis of peripheral blood leucocytes showed no abnormality. She had no signs of diabetic renal, retinal, or neurological changes. Insulin therapy was initiated under a diagnosis of diabetes millitus. Currently, her diabetes is well controlled with 27 units of insulin divided into two doses per day. Ultrasonographic study of the abdomen could not identify the body of the pancreas although the splenic vein was clearly visible. Only the head and the uncus of the pancreas were visible. Other abdominal organs seemed normal on ultrasonographic study. Abdominal CT scan confirmed the finding that most of the body and the tail of the pancreas were indeed absent (fig 3).

CASE 2

The family's fourth child (female) was born after 32 weeks of pregnancy. During the first seven months of pregnancy, the mother's diabetes was well controlled with dietary therapy alone. The birth weight of the baby was $1510 \mathrm{~g}$ $(-0.75 \mathrm{SD})$. She was noted to have cyanosis and tetralogy of Fallot was diagnosed by cardiac catheterisation. At 6 years of age, she underwent surgery to correct the anomaly. At the age of 14 years, routine school urine analysis showed glucosuria and she was referred to our hospital. On admission, she was in a fair condition. Her height was $140.3 \mathrm{~cm}(-2.9 \mathrm{SD})$ and weight was $27.5 \mathrm{~kg}(-2.8 \mathrm{SD})$. There were no external dysmorphic features and her
CASE 3 creas of their mother was re-examined. Abdominal CT scan showed that she also had hypoplasia of the pancreas. Only the head and the uncus of the pancreas were present and most of the body and the tail were absent.

\section{Discussion}

Partial agenesis/hypoplasia of the pancreas is a rare condition. Between 1966 and 1993, only 30 cases of pancreatic hypoplasia, partial agenesis, or short pancreas were reported in Eng-
Given the findings in cases 1 and 2, the pan-

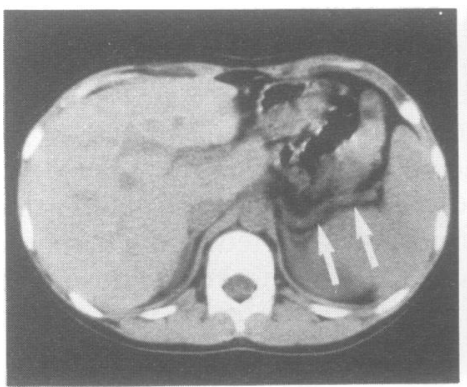

a

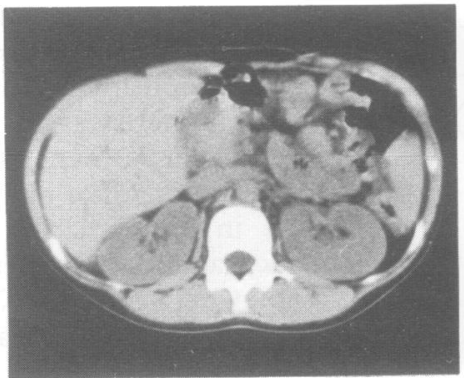

d
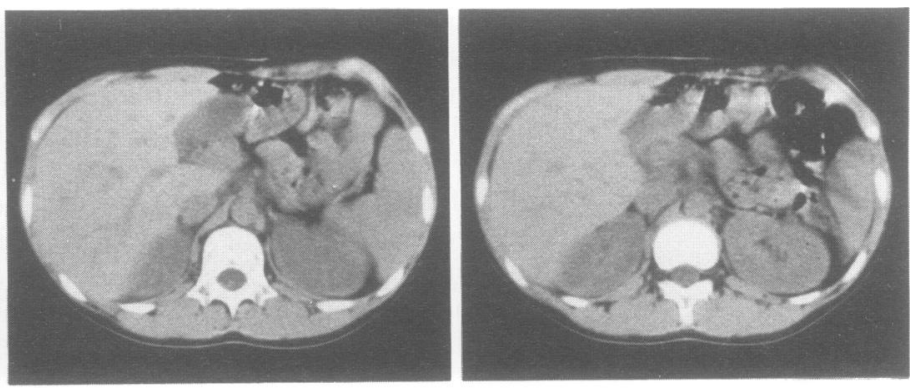

b

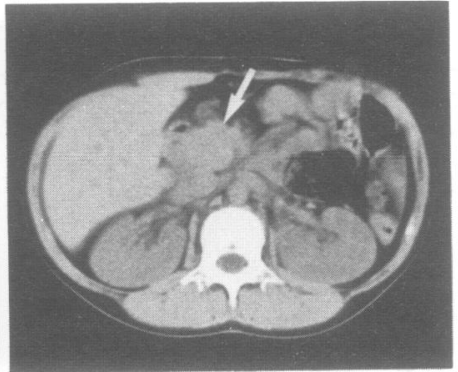

e

Figure 3 Serial CT scan sections through the upper abdomen in case 2. (a) Absence of the body of the pancreas. Arrows indicate the splenic vein. The body of the pancreas should be present at this level. (e) An arrow indicates the head of the pancreas. 
lish language publications. ${ }^{1-19}$ Most of these cases were sporadic except for two reports of familial cases. ${ }^{519}$ Of these 30 cases, 14 were not associated with other congenital anomalies. Other cases were associated with various congenital anomalies and, of these, polysplenia (13 cases) was the most common. ${ }^{3912131516}$ Other associated anomalies include vaginal atresia, ${ }^{10}$ pancreas division, ${ }^{8}$ duodenal atresia, ${ }^{8}$ absence of a kidney, ${ }^{13}$ intestinal malrotation, ${ }^{3}$ externally bilobular lungs, ${ }^{313}$ and congenital heart disease. ${ }^{2313}$ So far, only one sporadic case of a patient with a combination of pancreatic hypoplasia and congenital heart disease as the major anomalies has been reported. ${ }^{2}$ To the best of our knowledge, our case is the first report of familial occurrence of pancreatic hypoplasia and congenital heart disease.

Since the mother was not under the influence of drugs or chemicals and she was not overtly diabetic during pregnancy, the condition is most likely genetic and apparently the condition was inherited as an autosomal dominant trait. However, since our case involved only two generations, other modes of inheritance such as mitochondrial or $\mathrm{X}$ linked dominant inheritance cannot be excluded.

Although this condition seems to be rare, the true incidence could be higher because CT scan or abdominal ultrasonography are usually not included in the evaluation of paediatric diabetes mellitus. We suggest that, in cases of familial diabetes mellitus, morphological evaluation of the pancreas should be considered. We used CT scanning and ultrasonography because of their relative non-invasiveness. However, other techniques such as endoscopic retrograde pancreatography or magnetic resonance imaging (MRI) might have given better delineation of the pancreatic defect.

The cause of diabetes mellitus in this family is unclear. Among the 30 cases of pancreatic hypoplasia mentioned above, 12 cases developed diabetes mellitus and one had glucose intolerance. Both insulin dependent and nondependent diabetes mellitus were reported. The cause could be simply the small size, that is, the small number of islet cells. However, in all the patients in this family, diabetes mellitus manifested at a certain time in life. Before that time, they showed no signs of diabetes. This argues against a simple deficiency of islet cells as the cause of diabetes. On the other hand, the absence of inflammation of the pancreas (case 1 ), the absence of islet cell antibody (case 2), the measurable C-peptide excretion in the urine (case 2), and the slowly progressive diabetes of case 3 all suggest that the cause of the diabetes differed from the usual acute onset insulin dependent diabetes mellitus (IDDM). Therefore, it seems possible that the mechanism leading to diabetes mellitus in this family is similar to that of the adult onset non-insulin dependent diabetes mellitus (NIDDM).

In summary, we report a previously undescribed hereditary pancreatic hypoplasia associated with diabetes mellitus and congenital heart disease.

We thank Dr Ishikura, Noma (Radiology), and Dr Ichijima (Pathology) of our hospital for instructions and useful discussions.

1 Lechner GW, Read RC. Agenesis of the dorsal pancreas in an adult diabetic presenting with duodenal ileus. Ann Surg 1966;163:311-4.

2 Gurson CT, Tahsinoglu M, Yakacikli S, Ertugrul T. A case of agenesis of the dorsal pancreas with interventricular septal defect in an infant. Helv Paediatr Acta 1970;25:522-6.

3 Hatayama C, Wells TR. Syndrome of externally bilobed lungs with normal bronchial branch pattern, congenital heart disease, multiple spleens, intestinal malrotation and short pancreas: an apparently hitherto undefined malformation complex. Pediatr Pathol 1984;2:127-33.

4 Gilinsky NH, Del FG, Cotton PB, Lees WR. Congenital short pancreas: a report of two cases. Gut 1985;26:304-10.

5 Winter WE, Maclaren NK, Riley WJ, Toskes PP, Andres J, Rosenbloom AL. Congenital pancreatic hypoplasia: a syndrome of exocrine and endocrine
ciency. $\mathcal{F}$ Pediatr 1986;109:465-8.

6 Rosenstock E, Achtar E. A "short pancreas". Gastrointest Endosc 1986;32:296-7.

7 Bretagne JF, Darnault P, Raoul JL, et al. Calcifying pancreatitis of a congenital short pancreas: a case report with successful endoscopic papillotomy. Am $\mathcal{f}$ Gastroenterol 1987;82:1314-7.

8 Lehman GA, Kopecky KK, Rogge JD. Partial pancreatic agenesis combined with pancreas divisum and duodenum reflexum. Gastrointest Endosc 1987;33:445-8.

9 Shah KK, DeRidder PH, Schwab RE, Alexander TJ. CT diagnosis of dorsal pancreas agenesis. $\mathcal{F}$ Comput Assist Tomogr 1987;11:170-1.

10 Nishimori I, Okazaki $\mathrm{K}$, Morita $\mathrm{M}$, et al. Congenital hypoplasia of the dorsal pancreas: with special reference to duodenal papillary dysfunction. Am 7 Gastroenterol 1990;85:1029-33.

11 Wang JT, Lin JT, Chuang CN, et al. Complete agenesis of the dorsal pancreas - a case report and review of the iterature. Pancreas 1990;5:493-7.

12 Hadar H, Gadoth N, Herskovitz P, Heifetz M. Short pancreas in polysplenia syndrome. Acta Radiol 991;32:299-301.

13 Herman TE, Siegel MJ. Polysplenia syndrome with congenital short pancreas. Am f Roentgenol 1991;156:799-

14 Itoh H, Saito M, Ishimori M, Ohshiro K, Geo YY, Sakai T. A case report of dorsal pancreas agenesis diagnosed by MRI and ERCP. Radiat Med 1991;9:108-9.

15 Sriplung H. Polysplenia syndrome: a case with congenital heart block, infarction of a splenic mass, and a short pancreas. F Med Assoc Thai 1991;74:355-8.

16 Soler R, Rodriquez E, Comesana ML, Pombo F, Marini M Agenesis of the dorsal pancreas with polysplenia syndrome: CT features. $f$ Comput Assist Tomogr 1992;16:921-3.

17 Carroll PB, Finegold DN, Becker DJ, Locker JD, Drash AL. Hypoplasia of the pancreas in a patient with type I diabetes mellitus. Pancreas 1992;7:21-5.

18 Gold RP. Agenesis and pseudo-agenesis of the dorsal pancreas. Abdom Imaging 1993;18:141-4.

19 Wildling R, Schnedl WJ, Reisinger EV, et al. Agenesis of the dorsal pancreas in a woman with diabetes mellitus and in both of her sons. Gastroenterology 1993;104:1182-6. 